\title{
In vitro cytotoxic activity of five commercial samples of Tribulus terrestris Linn in Espírito Santo (Brazil)
}

\author{
Claudio Costa Oliveira Filho, ${ }^{1}$ Edgar Hell Kampke, ${ }^{1}$ Thais Souza Vargas, ${ }^{1}$ Nathacha Andrade \\ Salustriano, ${ }^{1}$ Rodrigo Scherer, ${ }^{1}$ Marcio Fronza, ${ }^{1}$ Bianca Prandi Campagnaro*,1
}

${ }^{1}$ Pharmaceutical Sciences Graduate Program, Vila Velha University, Vila Velha, Brazil

\begin{abstract}
The objective was to investigate the total saponin and protodioscin concentrations and the cytotoxicity in vitro, of five samples of the plant Tribulus terrestris, commercially available in the metropolitan region of Vitória - Espirito Santo, Brazil, and to compare them with the aqueous extract of the plant. The chromatographic profile and quantification of protodioscin in commercial samples and plant extract were evaluated by LC-MS/MS. The percentage of total saponins were determined by the colorimetric method. Extracts and protodioscin cytotoxicity were analyzed by the MTT assay in three cell lineages: fibroblasts (L929), ovarian cancer (Ovcar3) and murine hepatoma (Hepa1c1c7). All extracts displayed high levels of total saponins (207.2 to $780.3 \mathrm{mg} \mathrm{g}^{-1}$ of dry extract). The chromatographic profile revealed a wide diversity of compounds, and the saponin protodioscin was detected in only two extracts. One extract displayed high cytotoxicity, with $\mathrm{IC}_{50}$ values of 157.0, 38.2 and $7.4 \mu \mathrm{g} \mathrm{mL} \mathrm{m}^{-1}$ for the Ovcar3, Hepa1c1c7 and L929 cell lines, respectively. The other extracts displayed cytotoxic effects only at concentrations equal to or greater than $125.0 \mu \mathrm{g} \mathrm{mL}^{-1}$. Surprisingly, the most cytotoxic extract displayed the highest protodioscin concentration. Therefore, it is suggested that these products be marketed with caution, and followed-up by a certified healthcare professional.
\end{abstract}

Keywords: Tribulus terrestres/saponin/protodioscin/concentrations. Medicinal plants. Cytotoxicity/ in vitro.

\section{INTRODUCTION}

Tribulus terrestris is an herbaceous plant of the Zygophyllaceae family, with annual or occasionally perennial habits. It grows in semi-arid regions of various parts of the world such as the USA, Australia, Eastern Europe, the Mediterranean region of Europe, Africa, China and India (Dinchev et al., 2008). This grass also occasionally grows in the semi-arid regions of the Northeast of Brazil (Silva et al., 2014). Its name is associated with "Natural Viagra" due to popular folklore knowledge that it possesses aphrodisiac properties. Its popular use has also increased due to its possible androgenic properties (Lemos Júnior et al., 2011).

In Brazil, Tribulus terrestris extracts are sold in specialty stores, drugstores and popular markets, as an herbal remedy for androgen deficiency (Chhatre et

\footnotetext{
*Correspondence: B. P. Campagnaro. Pós-Graduação em Ciências Farmacêuticas, Universidade Vila Velha. Rua Mercúrio, s/n, Boa Vista 1, 29102-623 - Vila Velha-ES, BraSil. E-mail: biancacampagnaro@yahoo.com.br
}

al., 2014). Fitness enthusiasts and sports professionals consume this phytotherapic because they believe in its androgenic potential, promoting muscle mass gain and providing more energy for physical training. Another use that has prompted the search for this extract is its hypothetical activity in erectile dysfunction, as it is believed to enhance sexual performance by increasing sexual desire and penile blood flow (Chhatre et al., 2014).

Tribulus terrestris is considered a plant rich in saponins. Enriched fractions may present concentrations of around $45 \%$ protodioscin in its composition, this being one of the most abundant saponins (Kostova, Dinchev, 2005; ANVISA, 2013). Saponin-enriched fractions are widely marketed, being found in food supplements and pharmaceutical preparations available in Brazil and worldwide (Kostova, Dinchev, 2005).

Several studies have been conducted to determine the androgenic, aphrodisiac and cytotoxic effects of Tribulus terrestris. Previous studies associated its proerectile activity (Chhatre et al., 2014; Adaikan et al., 2000; 
Gauthaman, Adaikan, Prasad, 2002; Pokrywaka et al., 2014), as well as its cytotoxic effects on tumor cells ( $\mathrm{Hu}$, Yao, 2002; Neychev et al., 2007; Abudayyak et al., 2015) with the furostanol saponin protodioscin.

Considering the information described above, and prompted by the indiscriminate use of Tribulus terrestris, the aim of this study was to evaluate the chromatographic profile of five samples of the plant extract marketed in the metropolitan region of Grande Vitória, Brazil, as well as its cytotoxic effects in different cell lines, and to compare them with the aqueous extract of the plant.

\section{MATERIAL AND METHODS}

\section{Chemicals and Reagents}

3-(4,5-dimethylthiazol-2-yl)-2,5-diphenyl tetrazolium bromide (MTT), camptothecin (CPT) and cobalt chloride were purchased from Sigma Chemical Co, MO, USA. Saponin standard was purchased from Merck Co. (Germany). All solvents and reagents, including acetone, ethanol, methanol, ethyl acetate, and dimethyl sulfoxide (DMSO), were of analytical grade and were purchased from Vetec and Dinamic (Rio de Janeiro, Brazil).

\section{Acquisition of commercial samples of T. terrestris}

Five commercial samples of Tribulus terrestris were acquired in the consumer market of Grande Vitória, in May 2015. These samples were subjected to the same extraction procedures described in the section "extract preparation" for the preparation of aqueous extract of the plant, and were labelled samples 1, 2, 3, 4 and 5, respectively.

\section{Cell lines}

Murine hepatoma (Hepa 1c1c7) cells (ATTC ${ }^{\circledR}$ CRL-2026TM) fibroblasts (L929) (ATCC® CCL1TM) and human ovarian carcinoma cell line (Ovcar 3) (ATCC ${ }^{\circledR}$ HTB-161TM) (Cell Line Service, Rio de Janeiro, Brazil) were maintained in Dulbecco's modified Eagle's medium (DMEM) supplemented with 10\% fetal bovine serum (FBS), $100 \mathrm{IU} \mathrm{mL}^{-1}$ penicillin and $100 \mu \mathrm{g} \mathrm{mL}^{-1}$ streptomycin, at $37^{\circ} \mathrm{C}$, in a humidified atmosphere containing $5 \% \mathrm{CO}_{2}$ (all Sigma-USA).

\section{Plant material}

Tribulus terrestris Linn was collected in the city of Janaúba, in the state of Minas Gerais, Brazil, on June 2015 (Latitude -15.827240 and Longitude -43.278791).
The plant was taxonomically identified by the botanist Ms. Solange Zanotti Schneider, and a voucher specimen (UVVES2555) was deposited in the herbarium of the University of Vila Velha, Brazil.

\section{Tribulus terrestris extract preparation}

Aerial parts of Tribulus terrestris were dried to constant weight in an oven, at $40{ }^{\circ} \mathrm{C}$. Dried samples were pulverized by blending to a fine homogeneous powder prior to extraction. $10 \mathrm{~g}$ of pulverized plant material was impregnated in $100 \mathrm{ml}$ of ultrapure water, and placed in an ultrasonic bath at $35 \mathrm{kHz}$ frequency and $600 \mathrm{~W}$ power (Ultra Sonic Cleaner Unique Ultra 1440) for 30 min at room temperature. This procedure was repeated three times. Subsequently, the extracts were filtrated and the fractions combined and concentrated at $50{ }^{\circ} \mathrm{C}$ and stored at $4{ }^{\circ} \mathrm{C}$ until further use. This extract was labeled "Sample 6".

\section{Quantification of total saponin}

The colorimetric method described by Vigo, Narita and Marques (2003) was used to determine the total saponin concentration in the extracts. The content was calculated using the calibration curve of saponin standard from Merck ${ }^{\circledR}\left(6.25\right.$ a $\left.300.00 \mu \mathrm{g} \mathrm{mL}^{-1}\right)$. All the analyses were performed in triplicate, and the results expressed as mean \pm standard deviation. The total saponin was expressed in milligrams of saponin equivalent per gram of dry extract.

\section{ESI-LC-MS/MS analyzes - extract composition and quantification of protodioscin}

An Agilent Technologies 1200 series liquid chromatography-electrospray ionization-tandem mass spectrometer (Applied Biosystems API 3200) was used for the chromatographic analysis, with an electrospray ionization source in negative mode (LC-ESI-MS/MS). The data were processed using the software Analyst version 5.0. The chromatographic separation was performed in a Cortecs C18 ( $150 \times 4.6 \mathrm{~mm} ; 2.7 \mu \mathrm{m}$, Waters $\left.{ }^{\circledR}\right)$ column at $25^{\circ} \mathrm{C}$, with a volume of injection of $20 \mu \mathrm{L}$ and flow rate of $0.7 \mathrm{~mL} \mathrm{~min}{ }^{-1}$. The mobile phase used $0.1 \%$ acidified water with formic acid (A) from Sigma Aldrich with purity $\geq 98 \%$ and HPLC grade acetonitrile (B) from LiChrosolv. The total run time was 15 minutes, beginning with $90 \%$ of A up to 6 minutes, changing to $40 \%$ up to 11 minutes and returning to the initial condition at 13 minutes, where it remained for two minutes to equilibrate the column. 
The detection was performed in SRM mode (SelectedReaction Monitoring) and the transitions monitored from $1047,65 / 59$ and $1047,65 / 101$.

A protodioscin standard solution of $0.5 \mathrm{mg} \mathrm{mL}^{-1}$ and subsequent serial dilutions with methanol were prepared. The samples were prepared in ethanol 50\%. For the assessment of linearity, a calibration curve was prepared with five concentrations $(15.63 ; 7.81 ; 3.91 ; 1.95 ; 0.98 \mu \mathrm{g}$ $\left.\mathrm{mL}^{-1}\right)$. In three of these, seven replicates were performed to evaluate precision. The detection limit was defined as the concentration of analyte that produced a signal three times greater than the signal / noise ratio, and six times the quantification limit. The practical limit of quantification (PLQ) was defined as the lower limit of the calibration curve (Ganzera, Bedir, Khan, 2001).

\section{In vitro cytotoxicity}

The in vitro cytotoxic activity of the samples was determined using the colorimetric MTT assay according to Mosmann (1983). Briefly, Hepa 1c1c7, Ovcar 3 and Fibroblasts L929 cells were plated in 96-well plates with $7 \times 10^{5}$ cells $\mathrm{mL}^{-1}$, and after overnight incubation at 37 ${ }^{\circ} \mathrm{C}\left(5 \% \mathrm{CO}_{2}\right.$ and $95 \%$ air) cells were incubated for an additional $24 \mathrm{~h}$ in the presence or absence of increasing concentrations (15.6 - $\left.250.0 \mu \mathrm{g} \mathrm{mL}^{-1}\right)$ of aqueous extract of the samples. Camptothecin was used as positive control. After incubation, $100 \mu \mathrm{L}$ of 3-(4,5-dimethylthiazol- 2-yl)2,5-diphenyl tetrazolium bromide (MTT) $\left(1 \mathrm{mg} \mathrm{mL}^{-1}\right)$ was added per well, and the plate incubated for $2 \mathrm{~h}$. The formazan crystals formed were then dissolved with dimethyl sulfoxide (DMSO). Absorbance of purple formazan, proportional to the number of viable cells, was measured at $595 \mathrm{~nm}$ using a microplate reader (Molecular Devises, Spectra Max 190, USA). The experiments were carried out at least in triplicate.

\section{Statistical analysis}

Statistical analysis was performed using the softaware GraphPad Prism 5 (San Diego, CA, 176 USA). The results were expressed as mean \pm standard error of mean (SEM). Differences between mean values of multiple groups were analyzed by one-way analysis of variance (ANOVA) with Dunnett's test for post hoc comparisons, or two-way-ANOVA where appropriate. Statistical significance was considered at $\mathrm{p}<0.05$.

\section{RESULTS AND DISCUSSION}

In the present study, five commercial samples of Tribulus terrestris were analyzed and the results were compared with the aqueous extract of the plant. Quantitative analysis of the level of total saponins revealed that the samples displayed varying concentrations of this important chemical marker (Table I). Among the tested samples, the levels of total saponins ranged from 207.2 $\pm 0.8 \mathrm{mg}$ to $780.3 \pm 27.3 \mathrm{mg}$ of total saponins per gram of extract, in samples 3 and 5, respectively. These values represent a percentage variation of between $20.72 \%$ and $78.03 \%$. Moreover, it was observed that two of the tested samples had levels of total saponins above $50 \%$ (1 $53.93 \%$ and $2-57.56 \%)$ and another two had levels above $70 \%$ (4 $-75.07 \%$ and $5-78.03 \%$ ), demonstrating the high level of saponins contained in these samples (Kostova, Dinchet, 2005; ANVISA, 2013). The only sample that had low levels of saponins was sample 3, with $20.72 \%$.

TABLE I - Quantification of total saponins in commercial extracts and an aqueous extract of Tribulus terrestris

\begin{tabular}{cc}
\hline Samples & Saponin levels $\left(\mathbf{m g ~ g}^{-1}\right) *$ \\
\hline Sample 1 & $539.3 \pm 44.1$ \\
Sample 2 & $575.6 \pm 12.1$ \\
Sample 3 & $207.2 \pm 0.8$ \\
Sample 4 & $750.7 \pm 36.4$ \\
Sample 5 & $780.3 \pm 27.3$ \\
Sample 6 & $409.2 \pm 7.8$ \\
\hline
\end{tabular}

*The results were expressed in milligram equivalent of standard Merck ${ }^{\circledR}$ saponin per gram of dry extract. The tests were performed in triplicate and expressed as average \pm standard error.

The steroidal saponins of Tribulus terrestris are considered to be the factor responsible for the biological activity of products derived from this plant. However, the biological activity depends on the concentration and composition of these active saponins (Ganzera, Bedir, Khan, 2001; Dinchev et al., 2008). The presence and concentration of protodioscin, the main saponin reported in Tribulus terrestris, was verified by LC-ESI/MS/MS.

The linear range measured with the protodioscin standard was 0.98 to $15.63 \mu \mathrm{g} \mathrm{mL}^{-1}$, and the coefficient of determination (r2) was 0.9930 , which was satisfactory. In the accuracy evaluation, the three concentrations evaluated displayed a coefficient of variation lower than $6.10 \%$. The limits of detection and quantification were 0.01 and $0.02 \mathrm{mg} \mathrm{mL}^{-1}$, and the practical quantification limit was $0.98 \mathrm{~g} \mathrm{~mL}^{-1}$. The quantification of protodioscin in the samples showed that sample 1 had the highest protodioscin concentration $\left(442 \pm 6.6 \mathrm{mg} \mathrm{g}^{-1}\right)$, followed by sample 2 (3.7 $\left.\pm 0.5 \mathrm{mg} \mathrm{g}^{-1}\right)$. In samples $3,4,5$ and 6 , protodioscin was not detected. 
The LC/MS results revealed another intriguing fact. Some of the commercial analyzed samples, especially samples 1 and 3, exhibited a different chemical profile from the original plant extract (Sample 6), as can be observed in Figure 1. These observations are in line with current literature that describes a different distribution of steroidal saponins in Tribulus terrestris collected in different geographical regions, including Bulgaria, Greece, Serbia, Macedonia, Turkey, Georgia, Iran, Vietnam and India (Dinchev et al., 2008).
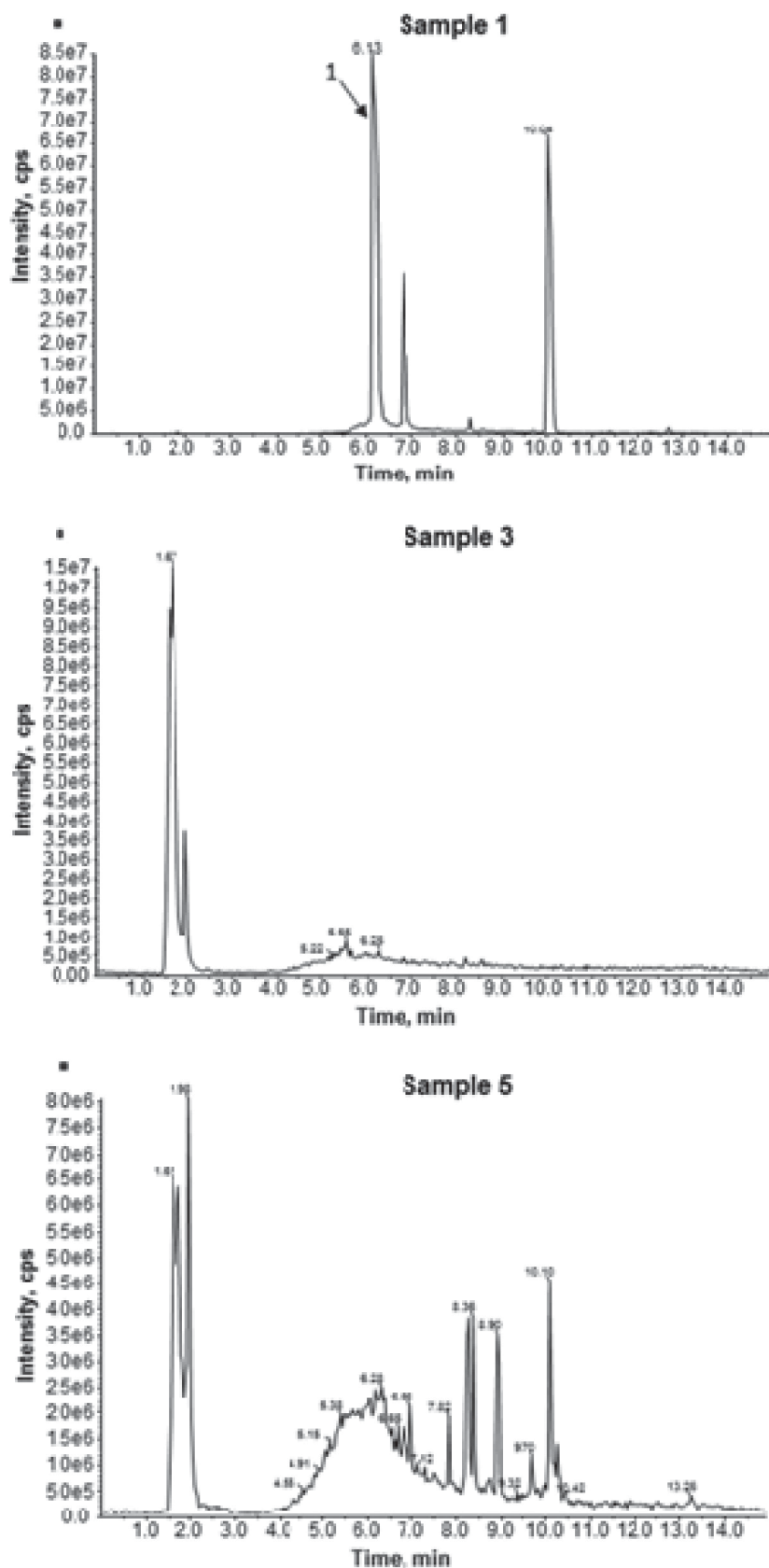

The furostanol saponin protodioscin was previously shown to exhibit cytotoxic activity against most cell lines from leukemia and solid tumors in the NCI's human cancer panel (Hu and Yao, 2002). Moreover, the aqueous extract of Tribulus terrestris has been shown to block proliferation and induces apoptosis in human liver cancer cells through the inhibition of NF- $\kappa B$ signaling (Kim et al., 2011).

Analysis of the cytotoxicity of protodioscin showed that from a concentration of $10 \times 10^{-6} \mathrm{~mol} \mathrm{~L}^{-1}$, this saponin was able to induce more than $50 \%$ cytotoxicity
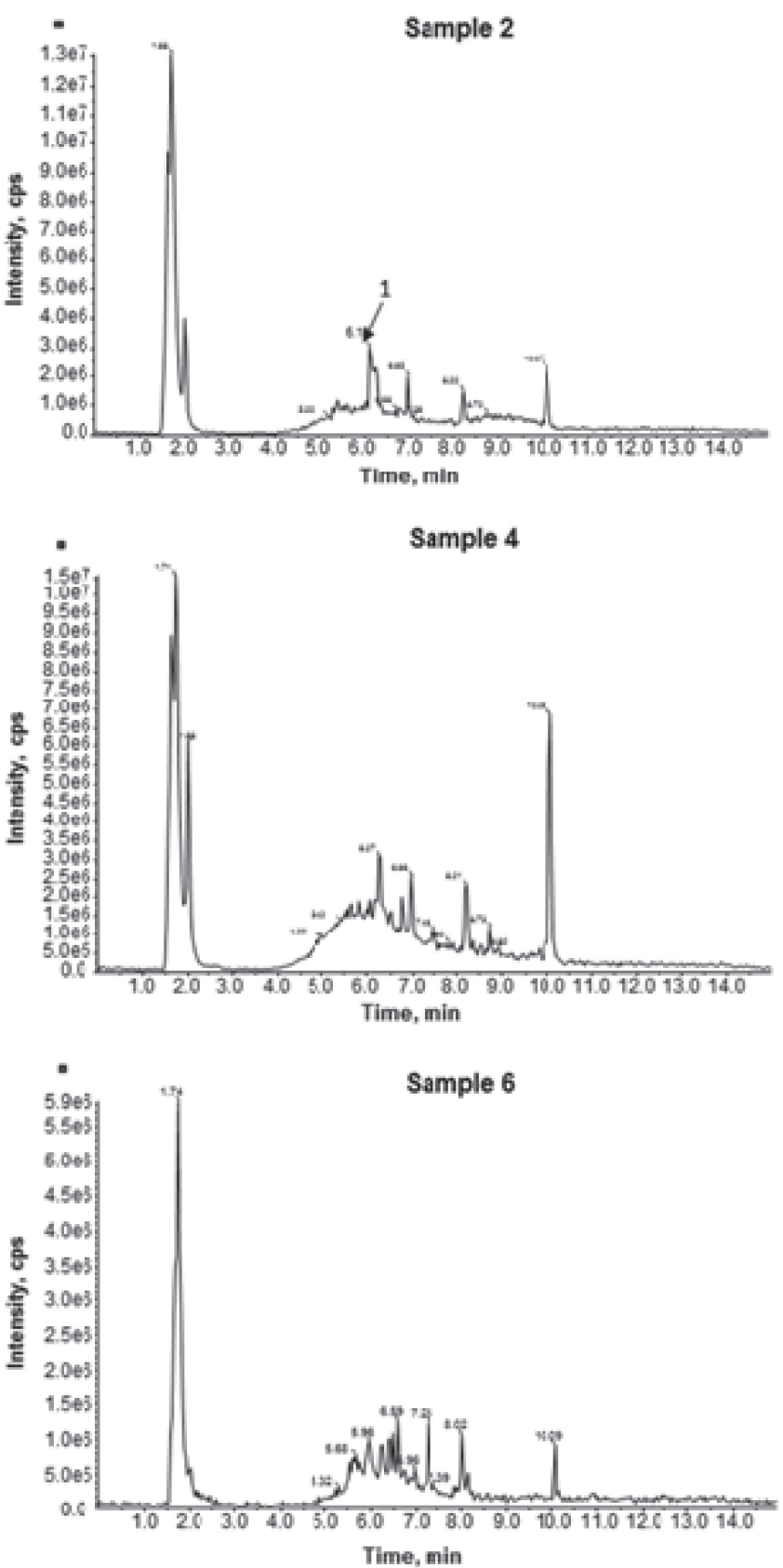

FIGURE 1 - Representative LC-MS profiles of commercially available aqueous extracts (Samples 1 to 5) of Tribulus terrestris and aqueous extract of the aerial parts of Tribulus terrestris (Sample 6). Peak 1 corresponds to protodioscin. 
(53.51) in the hepatoma cell line (h1c1c7), and at this same concentration, the positive control (camptothecin) induced $59.11 \%$ cytotoxicity. In the ovary carcinoma cell line (Ovcar 3), the protodioscin displayed 20.65\% cytotoxicity at $200 \times 10^{-6} \mathrm{~mol} \mathrm{~L}^{-1}$ and the positive control displayed $30.5 \%$ cell death at $10 \times 10^{-6} \mathrm{~mol} \mathrm{~L}^{-1}$. It is important to highlight that in the fibroblast cell line (L929), concentrations equal to or greater than $10 \times 10^{-6} \mathrm{~mol} \mathrm{~L}^{-1}$ of protodioscin were able to induce cytotoxicity higher than $50 \%$, as can be seen in Figure 2.

After verifying that protodioscin is cytotoxic not only to tumor cell lines but also to fibroblasts, we decided to evaluate the cytotoxicity of the commercial plant extracts. Considering that protodioscin is the main saponin found and, therefore, used in the characterization of Tribulus terrestris, we compared the cytotoxicity of the plant extracts sold in the region of Grande Vitória to the plant extract. As expected, the analysis of cytotoxicity of the extracts displayed a large variation between samples (Figures 3, 4 and 5). The most cytotoxic sample to all the cell lines analysed was extract 1 . In addition, sample 1 was cytotoxic to the Hepa $1 \mathrm{c} 1 \mathrm{c} 7$ cell line (70.8\%) at a concentration of $62.5 \mu \mathrm{g} \mathrm{mL}^{-1}$ (Figure 3), while the positive control induced $66.85 \%$ of cell death at $10 \times 10^{-6} \mathrm{~mol} \mathrm{~L}^{-1}$. As for the ovary carcinoma cell line, sample 1 induced $25.1 \%$ and $89.75 \%$ cytotoxicity at concentrations of $125 \mu \mathrm{g} \mathrm{mL}^{-1}$ and $250 \mu \mathrm{g} \mathrm{mL}^{-1}$, respectively, while the positive control displayed $39.25 \%$ cytotoxicity at $10 \times 10^{-6} \mathrm{~mol} \mathrm{~L}^{-1}$ (Figure 4 ). It is important to note that in the fibroblast cell line, sample 1 displayed cytotoxicity exceeding $50 \%$ from $31.3 \mu \mathrm{g} \mathrm{mL}^{-1}$. In both tumor cell lines, the less cytotoxic sample was extract 4 . In contrast, in fibroblasts, the extract with lower cytotoxicity was sample 5. Samples 2 and 3 were not cytotoxic at any of the concentrations tested in the tumor cell lines (h1c1c7 and Ovcar 3) and fibroblasts (L929) evaluated. It is important to highlight that sample 6 , obtained from the crude plant, displayed cytotoxicity higher than $50 \%$ at concentrations of 250 and $500 \mu \mathrm{g} \mathrm{mL}^{-1}$ in fibroblasts.

Given the indiscriminate use of herbal medicines in Brazil without proper guidance, the present study evaluated how these pharmaceutical products reach the end consumer. Two situations are of extreme relevance: first, and most importantly, that the product follows the guidelines of the regulatory agency ANVISA; and secondly, that the product is safe for consumption. This quality standard was performed by evaluating the presence of protodioscin, which is standardized at a minimum of $45 \%$ of the total of the extract by ANVISA. To evaluate the safety of these products, in vitro cytotoxicity assays were performed.

In the present study, we evaluated the action of protodioscin alone, as this is the reference saponin for Tribulus terrestris extracts (ANVISA, 2013). Our data showed that increased levels of protodioscin are cytotoxic to fibroblasts, suggesting that the consumption of Tribulus terrestris must be supervised by a health professional. It is also important to justify the choice of specific cell lines evaluated in this study. Protodioscin and other saponins isolated from Tribulus terrestris are clearly cytotoxic to tumor cell lines, specifically the hepatoma cell line, selected for the importance of the liver in the metabolism of drugs (Hu, Yao, 2002). On the other hand, the ovary cell

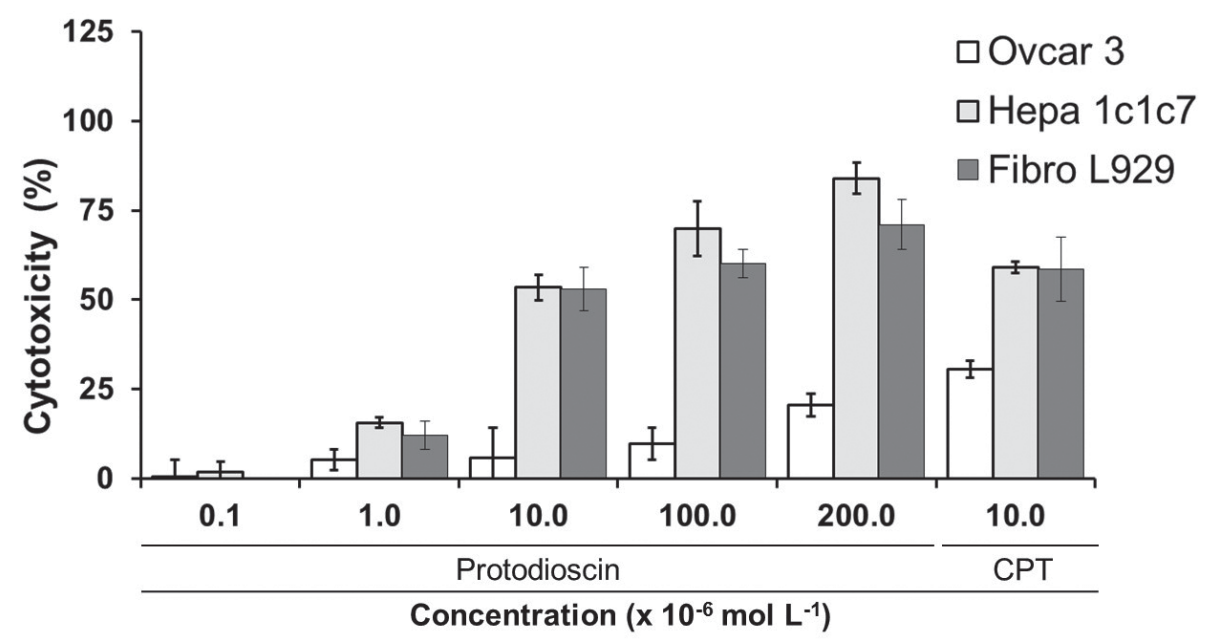

FIGURE 2 - Effect of protodiscin on cell viability. L929 fibroblasts, ovarium carcinoma (Ovcar 3) and hepatoma (Hepa 1c1c7) cells were treated with $0.1,1.0,10.0,100.0$ and $200.0 \times 10^{-6} \mathrm{~mol} \mathrm{~L}^{-1}$ of protodioscin for $24 \mathrm{~h}$. Values represent the percentage of cell death \pm SD of three independent experiments tested by the MTT assay. 


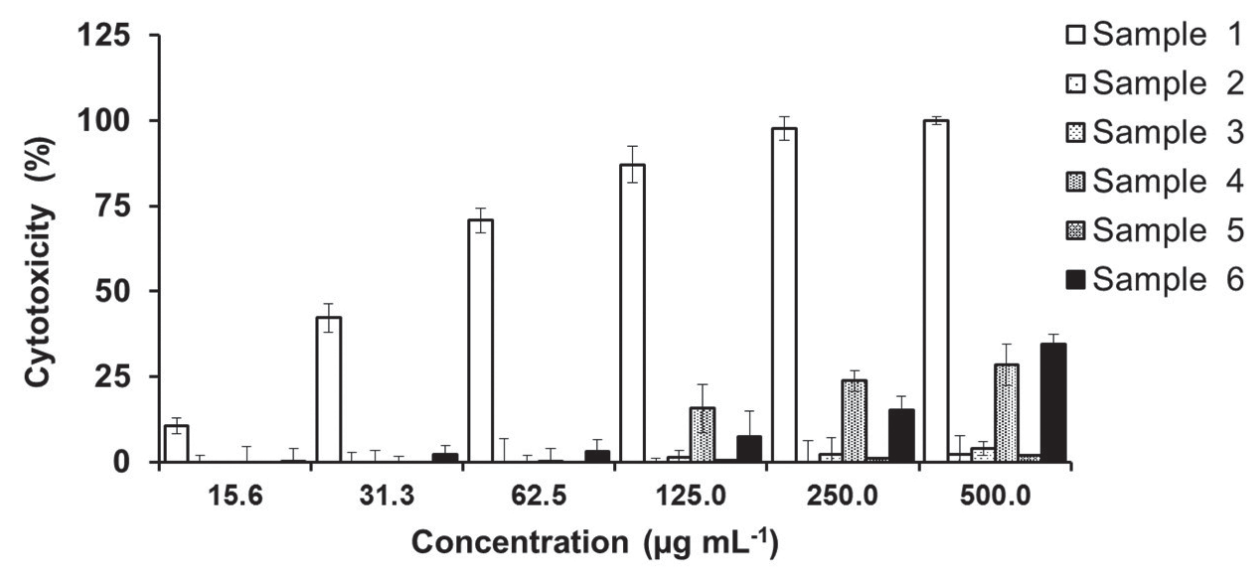

FIGURE 3 - Cytotoxic effects of commercial available aqueous extracts of Tribulus terrestris (Samples 1 to 5) and the aqueous extract of the aerial parts of Tribulus terrestris (Sample 6) evaluated against hepatocarcinona cell line (Hepa 1c1c7). Values represent the percentage of cell death $\pm \mathrm{SD}$ of three independent experiments tested by the MTT assay.

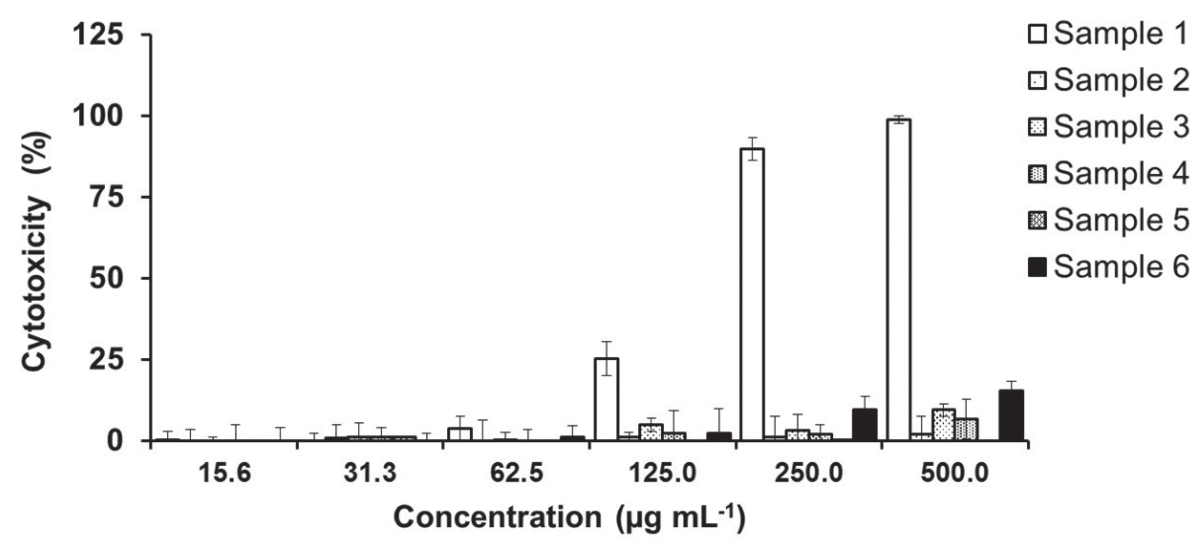

FIGURE 4 - Cytotoxic effects of commercially available aqueous extracts of Tribulus terrestris (Samples 1 to 5) and aqueous extract of the aerial parts of Tribulus terrestris (Sample 6) evaluated against the ovarium carcinoma cell line (Ovcar 3). Values represent the percentage of cell death \pm SD of three independent experiments tested by the MTT assay.

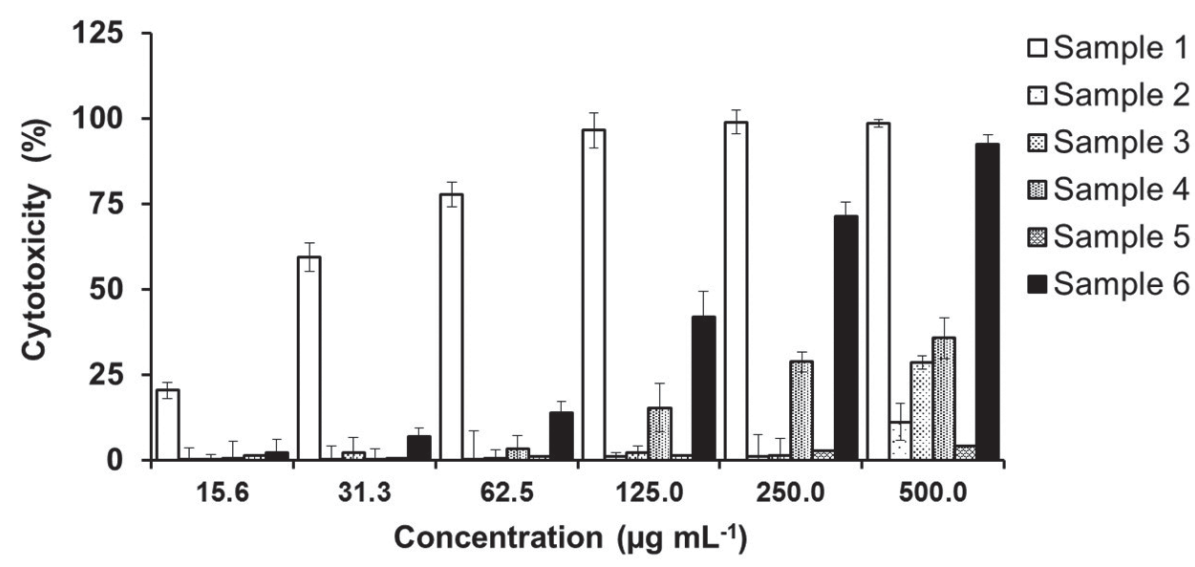

FIGURE 5 - Cytotoxic effects of commercial available aqueous extracts of Tribulus terrestris (Samples 1 to 5) and the aqueous extract of the aerial parts of Tribulus terrestris (Sample 6) evaluated against the normal fibroblasts cell line (L929). Values represent the percentage of cell death \pm SD of three independent experiments tested by the MTT assay. 
line was chosen because it is the most resistant cell line to protodioscin and other plant saponins (Hu, Yao, 2002).

Some factors must be taken into account to better understand the results. First, the quantity of protodioscin in the composition of the Tribulus terrestris which varies greatly, depending on where the plant is collected (Dinchev et al., 2008). This characteristic can be confirmed by the negligible levels of protodioscin found in the crude plant extract collected in the town of Janaúba (MG). Moreover, when assessing the concentration of protodioscin in the marketed extracts, only one sample showed protodioscin levels of around $45 \%$ of its composition, as recommended by ANVISA. Second, the saponins from Tribulus terrestris are considered cytotoxic (Sisto et al., 2012), mainly for tumor cells, and ovarian cancer cells (Ovcar) are less affected by this cytotoxicity (Hu, Yao, 2002). Considering the very low concentrations of protodioscin in most of the samples evaluated, it was expected that the extracts, including pure protodioscin, would lower cytotoxic activity on the cell lines studied.

After evaluating the data presented, only one sample (sample 1) had the expected quantity of protodioscin for an extract of Tribulus terrestris. During the industrialization process, there was probably a concentration of saponins enhancing the marketing of this extract. Furthermore, the presence of higher levels of protodioscin in the extract can increase its cytotoxicity, as well as its androgenic activity. Thus, the extract corresponding to sample 1 should be marketed with restrictions as an herbal medicine, requiring the prescription of a certified health professional. Sample 2 displayed a lower level of protodioscin when compared to sample 1 and, in spite of significant levels of saponins, its cytotoxicity was insignificant. The saponin type present in sample 2 is probably different from the protodioscin type. However, we cannot confirm this, as we did not identify the other saponin types present in the extracts. On the other hand, sample 3 displayed the lowest levels of saponins, and undetectable levels of protodioscin. In addition, the chromatogram obtained from this sample differs significantly from the other samples, including the plant extract, indicating that this sample cannot be classified as an extract of Tribulus terrestris. Samples 4 and 5 showed no significant cytotoxicity, with no significant presence of protodioscin being detected. Assessing the cytotoxicity of sample 6, we verified that the crude plant extract presents negligible levels of protodioscin. However, at concentrations of 250 and $500 \mu \mathrm{g} \mathrm{mL}^{-1}$, sample 6 was able to induce more than $50 \%$ of death in the fibroblast cell line, unlike the tumor cell lines evaluated in the study.

\section{CONCLUSIONS}

In conclusion, this study demonstrated the great variability in the profile of extracts of Tribulus terrestris marketed in the region of Grande Vitória, displaying considerable chromatographic differences when compared to the crude plant extract. In addition, we showed a directly relationship between the cytotoxicity of the extracts and the levels of protodioscin. The high levels of protodioscin, probably obtained by the industrialization process, showed a cytotoxic potential in tumor cell lines in vitro. Moreover, in spite of the negligible levels of protodioscin, the plant extract was shown to be cytotoxic to fibroblasts, suggesting that it must be tested in vivo to confirm the effects observed in the present study and, consequently, protect the end consumer.

\section{ACKNOWLEDGMENTS}

The authors thank the Fundação de Amparo à Pesquisa do Espírito Santo (FAPES), Coordenação de Aperfeiçoamento de Pessoal de Nível Superior (CAPES) and Conselho Nacional de Desenvolvimento Científico e Tecnológico $(\mathrm{CNPq})$ for the financial support. We also would like to thank Herbarium ${ }^{\circledR}$ for kindly providing one sample of T. terrestris.

\section{AUTHORS' CONTRIBUTIONS}

CCOF (Master's degree student) carried out the study running the laboratory work, analysis of the data, and drafting of the paper. EHK contributed to biological studies. NAS and TSV carried out the chromatographic analysis. RS, MF and BPC designed the study, supervised the laboratory work and contributed to a critical reading of the manuscript. All the authors have read the final manuscript and approved the submission.

\section{CONFLICTS OF INTEREST}

All authors declare no conflicts of interest.

\section{REFERENCES}

Agência Nacional de Vigilância Sanitária. ANVISA. Formulário para envio de contribuições em consulta pública $\mathrm{n}^{\circ} 14 / 2013$. Associação Nacional de Farmacêuticos Magistrais. São Paulo: ANVISA; 2013. [26 de dezembro de 2016]. p. 1314p. Disponível em: http:// http://formsus.datasus.gov.br/ novoimgarq/11451/1776099_163408.pdf. 
Abudayyak M, Jannuzzi AT, Özhan G, Alpertunga B. Investigation on the toxic potential of Tribulus terrestris in vitro. Pharm Biol. 2015;53(4):469-76.

Adaikan PG, Gauthaman K, Prasad RN, Ng SC. Proerectile pharmacological effects of Tribulus terrestris extract on the rabbit corpus cavernosum. Ann Acad Med Singapore. 2000;29(1):22-6.

Chhatre S, Nesari T, Somani G, Kanchan D, Sathaye S. Phytopharmacological overview of Tribulus terrestris. Pharmacogn Rev. 2014;8(15):45-51.

Dinchev D, Janda B, Evstatieva L, Oleszek W, Aslani MR, Kostova I. Distribution of steroidal saponins in Tribulus terrestris from diferent geographical regions. Phytochemistry. 2008;69(1):176-86.

Ganzera M, Bedir E, Khan IA. Determination of steroidal saponins in Tribulus terrestris by reversed-phase highperformance liquid chromatography and evaporative light scattering detection. J Pharm Sci. 2001;90(11):1752-58.

Gauthaman K, Adaikan PG, Prasad RN. Aphrodisiac properties of Tribulus Terrestris extract (Protodioscin) in normal and castrated rats. Life Sci. 2002;71(12):1385-96.

Hu K, Yao X. PROTODISCIN (NSC - 698 796): Its spectrum of citotoxity against sixty human cancer cell lines in an anticâncer drug screen panel. Planta Med. 2002;68(4):297-301.

Kim HJ, Kim JC, Min JS, Kim MJ, Kim JA, Kor MH, et al. Aqueous extract of Tribulus terrestris Linn induces cell growth arrest and apoptosis by down-regulating NF- $\kappa \mathrm{B}$ signaling in liver cancer cells. J Ethnopharmacol. 2011;136(1):197-203.
Kostova I, Dinchev D. Saponins in Tribulus terrestris chemistry and bioactivity. Phytochem Rev. 2005;4(2-3):111-37.

Lemos Júnior HPL, Lemos ALA, Lemos LMD. Tribulus terrestris. Diagn Tratamento. 2011; 16(4):170-3.

Neychev VK, Nikolova E, Zhelev N, Mitev VI. Tribulus terrestris $L$. are less toxic for normal human fibroblasts than for many cancer lines: influence on apoptosis and proliferation. Exp Biol Med. 2007;232(1):126-33.

Pokrywka A, Obminski Z, Malczewska-Lenczowska J, Fijalek Z, Turek-Lepa E, Grucza R. Insights into supplements with Tribulus Terrestris used by athletes. J Hum Kinet. 2014;41:99105.

Silva UCS, Oliveira RP, Harley RM, Giullietti AM. Flora da Bahia: Zygophyllaceae. Sitientibus Ser Ci Biol. 2014;14:1-5.

Sisto M, Lisi S, D'amore M, Lucro R, Carati D, Castellana $\mathrm{D}$, et al. Saponins from Tribulus terrestris L. protect human keratinocytes from UVB-induced damage. Photochem Photobiol. 2012;117:193-201.

Vigo CLS, Narita E, Marques LC. Validação da metodologia de quantificação espectrofotométrica das saponinas de Pfaffia glomerata (Spreng.) Pedersen Amaranthaceae. Rev Bras Farmacogn. 2003;13(Suppl 2):46-9.

Received for publication on $06^{\text {th }}$ January 2017 Accepted for publication on $14^{\text {th }}$ March 2017 